\section{Risk factors associated with post-stroke dementia: a systematic review and meta-analysis}

\author{
Jesada Surawan, ${ }^{1}$ Suchat Areemit, 2 \\ Somsak Tiamkao, ${ }^{3}$ \\ Theparak Sirithanawuthichai, 2 \\ Suprawita Saensak ${ }^{2}$ \\ 1Health Science Program, Faculty of \\ Medicine, Mahasarakham University; \\ 2Department of Medicine, Faculty of \\ Medicine, Mahasarakham University; \\ 3Department of Medicine, Faculty of \\ Medicine, Khon Kaen University, \\ Thailand
}

\begin{abstract}
This study aimed to evaluate the risk factors for prognostic of post-stroke dementia (PSD). A systematic review included case-control and/or cohort studies, we searched both published and unpublished literatures between 2000 to July 31, 2016. Two authors independently screened and selected research articles. If another one disagreed, the third author would be just along with his/her professionally. Moreover, Critical appraisal was measured by the quality (GRADE). Data collection was in the data extraction form. The Rev-Man 5.3 was used to estimate pooled data. The fixed-effect model will be used when the heterogeneity $\mathrm{I}^{2}$ $<50 \%$, whereas the random-effects model will be used when the heterogeneity $\mathrm{I}^{2} \geq 50 \%$. Result eight publications were pooled for measuring an association between risk factors and PSD by meta-analysis. There were 6 strongly PSD risk factors. The pooled relative ratio (RR) of atrial fibrillation was 1.68 , previous stroke 1.59 , myocardial infarction 1.40, hypertension 1.36 , diabetes mellitus 1.25 and previous transient ischemic attack 1.25 respectively. Un-pooled data from 13 publications reported that the risk factors for dementia in stroke patients were i) demographic factors, ii) vascular risk factors, iii) stroke factors, iv) stroke complications, and v) abnormalities on brain imaging. Strongly risk factors associated with increasing PSD risk were atrial fibrillation, previous stroke, myocardial infarction, hypertension, diabetes mellitus, and previous transient ischemic attack. Further studies, strongly risk factors need to investigate and develop the risk score for the prediction of dementia in stroke patients.
\end{abstract}

\section{Introduction}

Cerebrovascular disease (stroke) is com- mon and the major cause of death and physical disabilities around the world. ${ }^{1}$ The estimation of patients who die with stroke in 2020 will increase 2 times of the record in 1990, especially in developing countries.2,3 In Asian countries, stroke is the cause of death higher than the cardiovascular disease significantly. ${ }^{3-5}$ In Thailand, the death rate of stroke patients was 20.8 $/ 100,000$ population in 2008 and leveled up to $31.7 / 100,000$ population in 2012.4 From the previous study that traced patients with stroke during three months it was found that most patients have mild disability $(57.2 \%)$, some have severe disability (18.6\%), and a few have moderate disability $(9.4 \%) .5$ In addition, stroke also led to memory disturbance and dementia over 9.4 times compared with and without stroke, ${ }^{6}$ memory disturbance between $20-80$ percentage, 7,8 and the incidence of dementia was 5- 48 percentage. 3,4 Moreover, probability of recurrent stroke increased, 9,10 recurrent stroke was 33.3 percentage, ${ }^{11}$ the mortality rate of dementia after stroking was three times compared with and without, ${ }^{7}$ and the estimated cost of caring the dementia patients around the world is approximately 604,000 million US dollar. 12

Mechanism of disease, symptoms and risk factors, and mechanisms of post-stroke dementia may be the direct consequence of the vascular lesions of the brain. Second, post-stroke dementia may be caused by an associated asymptomatic Alzheimer pathology. Third, white matter changes may also contribute to dementia because they often indicate small-vessel disease and a higher risk of stroke recurrence and may lead to slight cognitive impairment. ${ }^{13}$ Besides the symptoms of neurological disorder, there are also signs of memory disturbance and dementia, and common symptoms such as slow thinking, easy to forget, deficiencies in language, mood, and behavioral changes. The patients reduced ability in their daily life until they no longer had any daily activities. 14,15 The symptoms usually occur at least 3 months after they had a stroke. Risk factors of dementia after stroking are caused by many factors. It was found that $66 \%$ of the patients are caused by stroke, and $33 \%$ caused by Alzheimer's disease. ${ }^{3}$ This may result from stroke and Alzheimer's disease or from other factors ${ }^{16,17}$ such as aging, low education level, diabetes mellitus, atrial fibrillation, myocardial infarction, hypertension, medial temporal lope atrophy and white matter changes. ${ }^{10,11,16,18-25}$

Currently, dementia is considered untreatable, and there are many factors that cause dementia. The previous study was unable to identify the factors that affect directly. Therefore, the researchers use systematic review methods, a review of the lit-
Correspondence: Suprawita Saensak, Gradutaed Studies Division, Faculty of Medicine, Mahasarakham University (MSU), 269 Talat Subdistrict, Mueang Maha Sarakham District, Maha Sarakham 44000, Thailand.

Tel. +66.985857491

E-mail: suprawita.s@msu.ac.th

Key words: Risk factors; Post-Stroke; Dementia; Systematic review; Alzheimer.

Conflict of interests: the authors declare no potential conflict of interest.

Conference presentation: abstract of this paper was presented at the 19th International Conference on Advance in Evidence-Based Medicine, 2017 during May 14-15, at Amsterdam, Netherlands.

Acknowledgments: the authors would like to thank Associate Professor Dr. Kittisak Sawanyawisuth who has advised the writing of manuscript, Department of Medicine, Faculty of Medicine, Khon Kaen University, Khon Kaen, Thailand, and graduated studied division, Faculty of Medicine, Mahasarakham University for supporting the research granted.

Received for publication: 8 May 2017. Accepted for publication: 14 June 2017

This work is licensed under a Creative Commons Attribution NonCommercial 4.0 License (CC BY-NC 4.0).

(C) Copyright J. Surawan et al., 2017

Licensee PAGEPress, Italy

Neurology International 2017:9:7216

doi:10.4081/nir.2017.7216

erature and knowledge, systematic and clear methods, data collection, and reviews of important studies in order to answer research questions and obtain findings from the review based on meta-analysis. In addition, a systematic review has the advantage such as clear methodology, reduces the bias in selection and exclusion study, the results have greater credibility. The researchers can compare the results to make generalization, find consistency of those studies, and summarize the reasons explaining the differences among the current studies. Thus, this research can suggest results with greater accuracy.

From the previous studies, it is evidence that vascular dementia (VAD), Alzheimer's disease and other risk factors were associated with the increased incidence of dementia, but these strong causes are still being debated. Therefore, the researchers are interested to study the risk factors for prognostic dementia in stroke patients. The 
study was a systematic review to collect the relative risks of dementia in stroke patients and the risk factors in former studies. The relative risks are analyzed by using Meta Analysis to synthesize the overall relative risks. This makes the relative risks more reliable. It can be used to identify important risk factors that cause dementia in stroke patients.

\section{Materials and Methods}

The systematic review was done according to the meta analysis of observational studies which are relevant to risk factors, dementia, and duration of post-stroke dementia, The scope of the review covers both case - control and cohort studies. We researched on both published and unpublished literatures dating from January 2000 to July 31, 2016 which consist of (1) electronic databases such as MEDLINE, Ovid, Science Direct, Cochrane Library and (2) gray literature sources including internal reports, conference proceedings, books and journal articles to answer the research question, study in the general population and study in hospital, no limitation on language, sample size and duration of follow-up. Studies of participants with stroke diagnosed by neurologist, confirmed case by CT scan or MRI in all age and gender, and studies of participants with post-stroke dementia diagnosed by neurologist and psychiatrist were confirmed by CT scan or MRI in all age and gender. The intervention or combination of interventions was given for searching risk factors and time relating to post-stroke dementia.

The researchers defined key words for searching in electronic databases with exploded medical subject headings (MESH) including keywords related to disease and its risk factors such as dementia, vascular dementia, stroke patients, post-stroke dementia, dementia after stroke, risk factors post-stroke dementia, and time to event post-stroke dementia, key words about the type of studies such as cohort or case-control, keywords associated with the study result such as odds ratio or relative risk or hazard ratio. The searching also included article criteria emphasizing risk factors for post - stroke dementia, selected studies or article quality, studies of patients with stroke and risk factors for dementia, measured dementia by standard criteria, and a follow up of patients at least 3 months after stroke. The search did not include article criteria on odds ratio, relative risk, and hazard ratio about the risk factors associated with dementia in stroke patients, unquali- fied articles, and articles without full text. Two reviewers search the literature and critical appraisal each article independently. If we had not unidentified the studies through the selection criteria and/or methodology, we would consult an expert's opinion or communicate with referees.

To extract data, two reviewers' derived data from all included articles, and disputes were resolved by consensus. Data were recorded in the table including general information (title, author), study characteristics (research objective, research design, study inclusion and exclusion criteria, number of participant, research instrument, follow-up), participant characteristics (age, gender, ethnicity, co-morbidities, location), intervention and setting (intervention, duration, setting), outcome data/results (statistical techniques used, outcomes).

The relative risk was performed with RevMan 5.3, pooled estimates of risk ratio by the Mantel-Haenszel method, verification of the accuracy of the risk factors using $95 \%$ confidence intervals, and relative risk is for cohort studies. Odds ratio is commonly for case-control, I2, Chi-squared ( $\chi^{2}$, or $\mathrm{Chi}^{2}$ ) and forest plots test are statistical test for heterogeneity. The fixed-effect model would be used when there was heterogene- ity $\mathrm{I}^{2}<50 \%$, whereas the random-effects model would be used when the heterogeneity indicated $\mathrm{I}^{2} \geq 50 \%$.

\section{Results}

The studies found a total of 429 articles from 5 databases including Cochrane Library, PubMed, Science Direct, Ovid and E-Thesis. This set of data was later reduced to 36 abstracts containing relevant risk factors for dementia after stroke. Fifteen abstracts were excluded because the result no associated with poststroke dementia, thirteen articles cannot calculate the data for the relative risks of dementia in stroke patients. The remaining 8 articles $20,21,23,26-30$ selected by the selection criteria can be calculated to identify the relative risks of dementia, as shown in Figure 1.

Table 1 shows the demographic details of hospital-based and population-based studies of dementia after stroke such as study design, and methods used to measure dementia in all the publications that were relevant to the eligible hospital-based and population-based studies of dementia after stroke. These include 7 hospital-based cohorts of consecutive patients with stroke and one population-based cross-sectional

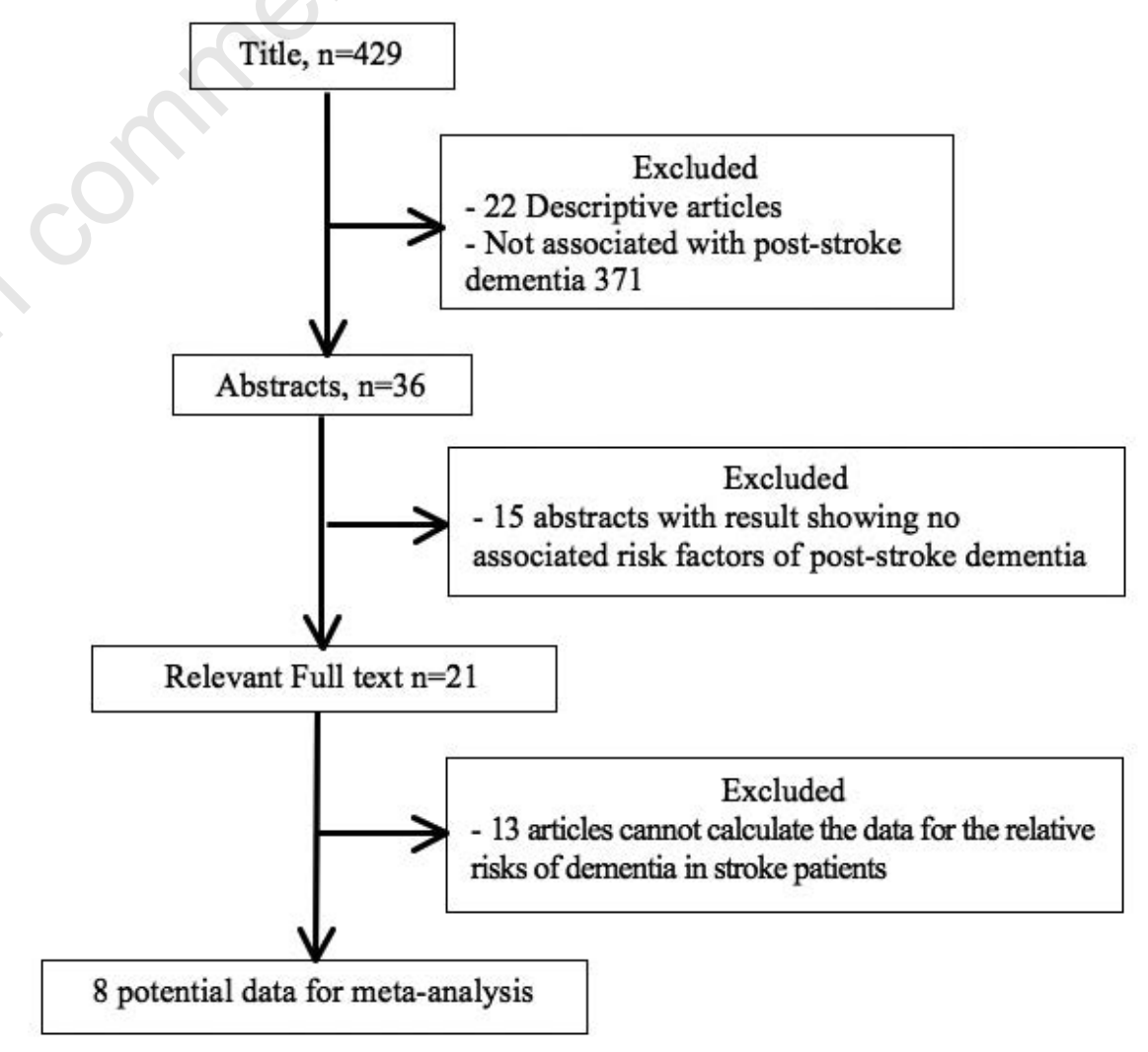

Figure 1. Literature search results. 
study. There were also differences in stroke type studies: 226,28 of 7 hospital-based studies of post-stroke dementia with only ischemic stroke. The diagnosis of dementia followed the method in the Diagnostic and Statistical Manual of Mental Disorders $3^{\text {th }}$ and 4 thedition (DSM-III, DSM-IV). The following stroke patients from one month to 24 years after a stroke. Found prevalence rates of dementia in hospital-based between $20-30.2 \% 21,23,26,27,31$ and $20.4 \%$ in population-based studies, 30 the average age of stroke patients with dementia 69-80 years as shown in Table 1.

Table 2 shows risk factors for poststroke dementia. Eight publications were pooled for measuring an association between risk factors and post-stroke dementia using meta-analysis. It was found that 6 strongly risk factors were associated with dementia including 1) atrial fibrillation (RR $1.68,95 \% \mathrm{CI} ; 1.28$ to 2.22 ) 2) previous stroke (RR 1.59, 95\%CI; 1.33 to 1.91 ) 3) myocardial infarction (RR 1.40, 95\%CI; 1.23 to 1.59 ) 4) hypertension (RR 1.36 , 95\%CI; 1.20 to 1.53$) 5$ ) diabetes mellitus (RR $1.25,95 \% \mathrm{CI} ; 1.11$ to 1.41 ) and 6) previous transient ischemic attack (RR 1.25, $95 \% \mathrm{CI} ; 1.08$ to 1.45 ), respectively. It was also found that heterogeneity of each study is not very high. However, the study of risk factors for atrial fibrillation is associated with dementia in stroke patients is $\mathrm{I}^{2}=72 \%$.

As part of a systematic review, determinants of post-stroke dementia included what follows. First, demographics and clinical characteristics of patients which showed increasing age associated with an increased risk of poststroke dementia in most studies. 16,18-21,23,25,32 Adding demographics factors showed that the risk of incident dementia elevated in relation to older age especially $\geq 80$ years (RR 4.66, $95 \% \mathrm{CI} ; 2.36$ to 9.22 ) and age 70 to 79 years (RR 2.68, 95\%CI; 1.52 to 4.74 ) versus age 60 to 69 years. ${ }^{28}$ Low education level was an independent predictor of post-stroke dementia10,11,16,22,25,32,33 which is highest in the low education category ( $\mathrm{HR} 1.46,95 \% \mathrm{CI}$; 1.18-1.81) followed by intermediate education category (HR 1.36, 95\%CI; 1.03 to 1.81 ). There is no significant association under observation in the high education category (HR 0.62, $95 \% \mathrm{CI} ; 0.25$ to 1.54$) .33$ Previous mental decline was the correlation of dementia in logistic regression analysis (OR $1.20,95 \% \mathrm{CI} ; 1.10$ to 1.40$).{ }^{31}$ Cognitive impairment before stroke risk of dementia after stroke showed that cognitive impairment before stroke was associated with potential covariates and diagnosis of poststroke dementia in the Helsinki Stroke Ageing Memory study cohort (OR 5.76, 95\%CI; 2.84 to 11.70$) .10$ Second, vascular risk factors such as diabetes mellitus were associated with an increased risk of dementia in stroke patients $10,11,16,20-22,24,32$ who had history of diabetes mellitus associated with incident demen-

Table 1. Demographic detail of hospital-based and population-based studies of dementia after stroke.

\begin{tabular}{|c|c|c|c|c|}
\hline $\begin{array}{l}\text { Author and year of } \\
\text { publication }\end{array}$ & $\begin{array}{l}\text { Study design } \\
\text { and setting }\end{array}$ & $\begin{array}{l}\text { Stroke type and } \\
\text { follow up }\end{array}$ & Exclusion criteria & Post-stroke diagnosis \\
\hline $\begin{array}{l}\text { Barba et al., } \\
200031\end{array}$ & $\begin{array}{l}\text { Prospective study, } \\
\text { Hospital Severo Ochao, Spain }\end{array}$ & $\begin{array}{l}\text { Total stroke, } \\
3 \text { months }\end{array}$ & $\begin{array}{l}\text { Prior stroke, TIA, subarachnoid hemorrhage } \\
\text { and stroke associated with } \\
\text { other primary brain lesions }\end{array}$ & $\begin{array}{l}\text { DSM III-R } \\
\text { DSM IV }\end{array}$ \\
\hline $\begin{array}{l}\text { Desmond et al., } \\
200228\end{array}$ & $\begin{array}{l}\text { Longitudinal study, } \\
\text { Columbia Presbyterian } \\
\text { Medical center }\end{array}$ & $\begin{array}{l}\text { Ischemic } \\
3 \text { months, Annually up } \\
\text { to } 4 \text { years }\end{array}$ & $\begin{array}{l}\text { Dysphasia, unable to speak } \\
\text { English or Spanish, low GCS, } \\
\text { age }<60 \text { years }\end{array}$ & DSM III-R \\
\hline $\begin{array}{l}\text { Tang et al., } \\
200427\end{array}$ & $\begin{array}{l}\text { Cohort study, } \\
\text { Prince of Wales Hospital, China }\end{array}$ & $\begin{array}{l}\text { Total stroke, } \\
3 \text { months } \\
\text { sy }\end{array}$ & $\begin{array}{c}\text { TIA, subdural hematoma, } \\
\text { or subarachnoid hemorrhage } \\
\text { and history of central nervous } \\
\text { system disease (tumor, trauma, hydrocephalus, } \\
\text { or Parkinson disease) }\end{array}$ & DSM IV \\
\hline $\begin{array}{l}\text { Zhou et al., } \\
2004^{26}\end{array}$ & $\begin{array}{l}\text { Prospective study, } \\
\text { Daping Hospital, China }\end{array}$ & $\begin{array}{l}\text { Ischemic, } \\
3 \text { months }\end{array}$ & $\begin{array}{c}\text { Presence of a con-comitant } \\
\text { neurological disorder potentially } \\
\text { affecting cognitive function } \\
\text { (e. g., severe Parkinson's disease), } \\
\text { serious illness, severe hearing and visual }\end{array}$ & DSM IV \\
\hline $\begin{array}{l}\text { Klimkowicz-Mrowiec } \\
\text { et al., } 2006^{21}\end{array}$ & $\begin{array}{c}\text { Cohort study, } \\
\text { Cracow Hospital, Poland }\end{array}$ & $\begin{array}{l}\text { Total stroke, } \\
3 \text { months }\end{array}$ & $\begin{array}{c}\text { Age }<40 \text { years, } \\
\text { no reliable informant, other brain lesion }\end{array}$ & DSM IV \\
\hline $\begin{array}{l}\text { Tamam et al., } \\
200823 \\
\text { Unive }\end{array}$ & $\begin{array}{l}\text { Prospective study, } \\
\text { Dicle } \\
\text { University Faculty } \\
\text { versity Faculty of Medicine, Turkey }\end{array}$ & $\begin{array}{l}\text { Total stroke, } \\
3 \text { months }\end{array}$ & $\begin{array}{c}\text { Subdural hematoma, } \\
\text { subarachnoid hemorrhage } \\
\text { or posttraumatic } \\
\text { hemorrhage, and history } \\
\text { of central nervous system disease } \\
\text { (tumor, trauma, hydrocephalus, } \\
\text { or Parkinson disease), } \\
\text { Unconsciousness, serious aphasia. }\end{array}$ & DSM IV \\
\hline $\begin{array}{l}\text { Yang et al., } \\
2015^{20}\end{array}$ & $\begin{array}{l}\text { Cross-sectional Cohort study, } \\
\text { University -affiliated hospital, } \\
\text { Hong Kong }\end{array}$ & $\begin{array}{l}\text { Total stroke, } \\
3 \text { to } 6 \text { months }\end{array}$ & $\begin{array}{l}\text { Severe language impairment, } \\
\text { presence of terminal illness, } \\
\text { clinically significant psychiatric } \\
\text { comorbidity, or history of dementia } \\
\text { before stroke }\end{array}$ & DSM IV \\
\hline $\begin{array}{l}\text { Bejot et al., } \\
2011^{30}\end{array}$ & $\begin{array}{l}\text { Cross-sectional study, } \\
\text { Dijon, France } \\
\text { Population-based }\end{array}$ & $\begin{array}{l}\text { Total stroke, } \\
1 \text { month to } 24 \text { years }\end{array}$ & $\mathrm{NA}$ & $\begin{array}{l}\text { DSM III-R } \\
\text { DSM IV }\end{array}$ \\
\hline
\end{tabular}

TIA, transient ischemic attack; DSM, Diagnostic and Statistical Manual of Mental Disorders; GCS, Glasgow Coma Scale; NA, not available. 
tia (OR 1.90, 95\%CI; 1.15 to 3.16$) .20$ Hypertension was independently associated with the risk of post-stroke dementia. Multivariate analysis of predictors of poststroke dementia showed that hypertension was associated with an increased prevalence of poststroke dementia (OR 1.38, 95\% $\mathrm{CI} ; 1.05$ to 1.82). ${ }^{30}$ Atrial fibrillation was associated with an increased prevalence of post-stroke dementia. $16,19,23$ Multivariate analysis of predictors of post-stroke dementia demonstrated that atrial fibrillation was associated with dementia in stroke patients which is statistically significant (OR 1.29, 95\% $\mathrm{CI} ; 1.02$ to 1.63 ). ${ }^{30}$ Myocardial infarction was independent predictors of dementia in stroke patients.(16) In population based study the result showed that myocardial in fraction was associated with an increased prevalence of post-stroke dementia (OR 1.35, 95\% $\mathrm{CI}$; 1.06 to 1.72 ). ${ }^{30}$ Tobacco was associated with post-stroke dementia.10,19,24 Cohort study found that smoker associated with potential covariates and diagnosis of post-stroke dementia (OR 1.51, 95\%CI; 0.89-2.58) ${ }^{10}$ and alcohol consumption risk factors were more frequent in demented patients than no demented patients (OR 1.87, 95\%CI; 1.02-3.44). ${ }^{26}$ Third, stroke factors such as the previous stroke has been indicated as a risk factor for poststroke dementia. ${ }^{11,18,22}$ A study on frequency and predictors of dementia after ischemic stroke showed that prior stroke was independent predictors of dementia (OR 2.53, 95\% CI; 1.42 to 4.51). ${ }^{26}$ Recurrence stroke risk factors were significantly associated with post-stroke dementia. 11,22,25 In systematic review and meta-analysis, it was found that recurrence stroke was associated with dementia (OR 2.3, 95\%CI; 1.5-3.5). ${ }^{22}$ Fourth, stroke complications showed that complication of stroke was associated with post-stroke dementia including incontinence ${ }^{11}$ (OR 6.4, 95\%CI; 4.5-9.2), 22 acute confusion ${ }^{11}$ (OR 2.8, 95\% ${ }_{0}$; 1 1.5-5.3), ${ }^{22} \mathrm{HI}$ episodes ${ }^{11}$ (OR 2.4, 95\%CI; 1.4-4.2), 22 early seizures ${ }^{11}$ (OR 5.4, 95\%CI; 2.4-12.1).22 (5) Abnormalities on brain imaging included leukoaraiosis (OR 2.5, 95\%CI; 1.9-3.4), Atrophy (OR 2.6, 95\%CI; 1.16.3), medial temporal lobe atrophy (OR 2.7, $95 \% \mathrm{CI} ; 1.8-4.2),{ }^{22}$ size and number of lesions (OR 14.38, 95\%CI; 1.55-132.68), ${ }^{23}$ and white matter changes (OR 1.16, 95\%

\section{Discussion}

According to the result of this study, it was found that the memory disturbance between $20-80$ percentage 7,8 and the incidence of dementia after stroking was 5 $48 \%$. 3,4,11-16 Moreover, the incident of dementia after recurrent stroke was $33.33 \% .{ }^{11}$ Factors independently associated with dementia in stroke patients were as follows: atrial fibrillation, the previous stroke, myocardial infarction, hypertension, diabetes mellitus, and the previous transient ischemic attack.

The risk of dementia is higher in stroke patients with atrial fibrillation; it was found that patients with atrial fibrillation had more severe stroke events than those without fibrillation. In addition, both pre- and poststroke dementia presumably were relevant to an atrial fibrillation depending on the increased age, and an atrial fibrillation was also related to multiple and recurrent strokes and increased severity of stroke. For some evidences, an atrial fibrillation was relevant to cognitive impairment and hip- pocampal atrophy with no symptomatic stroke or silent infarction. 34,35 The previous studies $26,30,31,36-39$ and the results of our study have shown that atrial fibrillation was associated with an increased risk of poststroke dementia. Moreover, the result of this study found that stroke patients with atrial fibrillation risk of dementia were 1.68 times compared with stroke patients without atrial fibrillation statistically significant.

The stroke significance in the etiology of post-stroke dementia was pointed out with increased risk that was related to previous symptomatic stroke, prior asymptomatic stroke on imaging, recurrent stroke, multiple stroke lesions, aphasia, stroke severity, hemorrhagic stroke, and infarct volume. A recent study indicates that infarcts in multiple areas are more likely to occur than infarcts in a single area that cause dementia. 40 The authors suggested that infarcts in several locations cause intracerebral circuit interruption, and infarcts and functional cortical disconnection can be caused by extensive white matter lesions and/or pre-existing neuronal damage. Prior or recurrent stroke has been indicated as a risk factor for post-stroke dementia26,28,31,41 Kokmen et al.42's study in population-based found that second stroke was significant independent predictors of dementia in a multivariate Cox proportional hazards model. Tatemichi et al. ${ }^{14}$ concluded that prior stroke was considered as the most important predictor of dementia. In this study, the previous stroke is associated with dementia in stroke patients were 1.59 times compared with stroke patients without previous stroke statistically signifi-

Table 2. Pooled risk ratios for factors associated with post-stroke dementia.

\begin{tabular}{|c|c|c|c|c|c|}
\hline Risk factors & Number of studies & $\begin{array}{c}\text { Patients with factors } \\
\text { Events/total }\end{array}$ & $\begin{array}{c}\text { Patients without factors } \\
\text { Events/total }\end{array}$ & RR $(95 \% \mathrm{CI})$ & $I^{2}$ \\
\hline Atrial fibrillation & $720,21,26-28,30,31$ & $246 / 941$ & $859 / 4761$ & $\begin{array}{c}\text { RR 1.68, } \\
\text { 95\%CI; } \\
1.28-2.22\end{array}$ & 72 \\
\hline Previous stroke & $621,23,26-28,31$ & $123 / 360$ & $273 / 1,239$ & $\begin{array}{c}\text { RR 1.59, } \\
\text { 95\%CI; } \\
1.33-1.91\end{array}$ & \\
\hline Myocardial infarction & $621,23,26,28,30,31$ & $221 / 771$ & $773 / 3,750$ & $\begin{array}{c}\text { RR } 1.40, \\
95 \% \mathrm{CI} \\
1.23-1.59\end{array}$ & 14 \\
\hline Hypertension & $720,23,26-28,30,31$ & $802 / 3,773$ & $291 / 1,845$ & $\begin{array}{c}\text { RR 1.36, } \\
95 \% \mathrm{CI} ; \\
1.20-1.53\end{array}$ & 46 \\
\hline Diabetes mellitus & $820,21,23,26-28,30,31$ & $273 / 1,231$ & $864,4,492$ & $\begin{array}{c}\text { RR 1.25, } \\
\text { 95\%CI; } \\
1.11-1.41\end{array}$ & 0 \\
\hline Previous transient ischemic attack & $721,23,26-28,3031$ & $162 / 599$ & $887 / 4,201$ & $\begin{array}{l}\text { RR 1.25, } \\
\text { 95\%CI; } \\
1.08-1.45\end{array}$ & 16 \\
\hline
\end{tabular}

$\mathrm{RR}$, risk ratio; $\mathrm{Cl}$, confidence interval. 
cant. Myocardial infarction was an important determinant of dementia associated with multiple cerebral infarctions 43 and a higher prevalence of cerebral small vessel disease. ${ }^{44}$ People with a history of myocardial infarction risk of dementia were 5 times at risk compared with those without a history of myocardial infarction. 45 Similar to other studies, 26,30 the researchers found that myocardial infarction was associated with an increased prevalence of post-stroke dementia. The present study demonstrates that stroke patients with myocardial infarction showing risk of dementia were 1.40 times compared with stroke patients without myocardial infarction statistically significant.

Hypertension may be masked by its high contribution to stroke, and recurrent stroke has shown to be a risk factor for poststroke dementia.41,42,46 Some studies 31 found that stroke patients with high blood pressure correlate of dementia and other studies 26,30 also found that hypertension associated with an increased prevalence of post-stroke dementia. In contrast, other studies 23,28 found that hypertension have not been associated with increased risk of dementia in stroke patients. The result of this study found that stroke patients with hypertension risk of dementia were 1.36 times compared with stroke patients without hypertension statistically significant.

Diabetes is known as risk factor of dementia and mild cognitive impairment, and it relates to both pre- and post-stroke dementia. Moreover, the age also relates to physiological decline, and diabetes interrupts micro vascular functions through several mechanisms such as excess production of reactive oxygen species, activation of protein kinase $\mathrm{C}$ and receptor for advanced glycation endproducts. In addition, studies in animal indicate that diabetes also affects post-stroke brain damage. ${ }^{47}$ and there is evidence that diabetes is associated with reduced recovery of cognitive function after stroke. ${ }^{48}$ Diabetes mellitus has been associated with various adverse health effects, and it was found that patients with diabetes mellitus were more likely than normal patients to have low MMSE49 reduced cerebral blood flow associated with impaired cerebral auto regulation, increased blood viscosity, and greater prevalence of underlying intracranial large-or small-artery disease. 50 Similarly, the reported association between stroke patients with and without diabetes mellitus of other studies $20,21,26,30,31,39,46$ found that diabetes mellitus associated with an increased prevalence of post-stroke dementia. The present study showed that stroke patients with diabetes mellitus risk of dementia were 1.25 times compared with stroke patients without diabetes mellitus statistically significant.

It is well known that both ischemic stroke and transient ischemic attack (TIA) are associated with vascular dementia. Vascular dementia is the second most common form of dementia. In the present study, reported that the previous transient ischemic attack is associated with dementia in stroke patients. It was found that stroke patients with previous transient ischemic attack risk of dementia were 1.25 times compared with stroke patients without previous transient ischemic attack statistically significant. Consistent with other studies $26,30,31$ that reported association between stroke patients with and without previous transient ischemic attack found that previous transient ischemic attack correlate of dementia. In contrast other studies 21,28 showed that previous transient ischemic attack have not been associated with dementia in stroke patients.

Post-stroke dementia is an important cause of disabilities; it affects memory, thinking, orientation, comprehension, calculation, learning capacity, language, and judgment. Our finding of risk factors poststroke dementia can useful for properly information patients and cares, planning service and promotion for reduces risk factors post-stroke dementia.

\section{Limitation of the study}

Limitations of this study can be bias of studies. The observational study underwent some difficulty containing random sampling selection bias. In addition, a systematic review is also likely to be affected by publication bias, which arose when researchers conducted a research article based on the databases MEDLINE, Ovid, Science Direct, Cochrane Library, and gray literature which gave results of some of the unpublished articles or have been published in other unselected databases.

\section{Conclusions}

In conclusion, the authors would like to strongly recommend that risk factors associated with increased risk of post-stroke dementia were atrial fibrillation, previous stroke, myocardial infarction, hypertension, diabetes, and previous TIA. However, there were other risk factors related to dementia. Thus, the researchers need to investigate and develop the risk score value to forecast the dementia incident in stroke patients in the further studies.

\section{References}

1. Guerchet MM, Mouanga P, Bandzouzi $\mathrm{AM}$, et al. Prevalence of dementia in elderly living in two cities of Central Africa: the EDAC survey. Dementia Geriatric Cogn Dis 2010;30:261-8.

2. Senanarong VP, Sukhatunga N, Prayoonwiwat $\mathrm{K}$, et al. Cognitive status in the community dwelling Thai elderly. J Med Assoc Thailand 2001;84:408-16.

3. Henon H, Durieu I, Guerouaou D, et al. Poststroke dementia incidence and relationship to prestroke cognitive decline. Neurology 2001;57:1216-22.

4. Fernández MC-F, Pérez de las Heras J, Mandaluniz-Lekumberri $\mathrm{S}$, et al. Prevalencia de la demencia en mayores de 65 años en una comarca del País Vasco. Rev Neurol 2008;46:89-96.

5. Grau AJ, Weimar C, Buggle F, et al. Risk factors, outcome, and treatment in subtypes of ischemic stroke the German stroke data bank. Stroke 2001;32:255966.

6. Keskinoglu PG, P1cakciefe H, Bilgic M, et al. The prevalence and risk factors of dementia in the elderly population in a low socio-economic region of Izmir, Turkey. Arch Gerontol Geriatrics 2006;43:93-100.

7. Tatemichi T, Paik M, Bagiella E, et al. Dementia after stroke is a predictor of long-term survival. Stroke 1994;25:1915-9.

8. Mellon L, Brewer L, Hall P, et al. Cognitive impairment six months after ischaemic stroke: a profile from the ASPIRE-S study. BMC Neurol 2015; $15: 1$.

9. Mathers C, Fat DM, Boerma JT. The global burden of disease: 2004 update. Washington, DC: World Health Organization; 2008.

10. Sibolt G, Curtze S, Melkas S, et al. Poststroke dementia is associated with recurrent ischaemic stroke. J Neurol Neurosurg Psych 2013;84:722-6.

11. Pendlebury ST. Stroke-related dementia: rates, risk factors and implications for future research. Maturitas 2009;64:165-71.

12. Wimo A, Jönsson L, Bond J, et al. The worldwide economic impact of dementia 2010. Alzheimer Dementia 2013;9:1-11.

13. Pasquier F, Leys D. Why are stroke patients prone to develop dementia? J Neurol 1997;244:135-42.

14. Xu YY, Shang JH. Meta-analysis of risk factors for Parkinson's disease dementia. Translational neurodegeneration. 2016;5:1. 
15. Lin J-H, Lin R-T, Tai C-T, et al. Prediction of poststroke dementia. Neurology 2003;

61:343-8.

16. Leys D, Hénon H, MackowiakCordoliani M-A, Pasquier F. Poststroke dementia. Lancet Neurol 2005;4:752-9.

17. Henon H, Pasquier F, Durieu M, et al. Preexisting dementia in stroke patients baseline frequency, associated factors, and outcome. Stroke 1997;28:2429-36.

18. Henon H, Pasquier F, Leys D. Poststroke dementia. Cerebrovasc Dis 2006;22:61-70.

19. Melkas S, Oksala NK, Jokinen H, et al. Poststroke dementia predicts poor survival in long-term follow-up: influence of prestroke cognitive decline and previous stroke. J Neurol Neurosurg Psych 2009;80:865-70.

20. Yang J, Wong A, Wang Z, et al. Risk factors for incident dementia after stroke and transient ischemic attack. Alzheimer Dementia 2015;11:16-23.

21. Klimkowicz-Mrowiec A, Dziedzic T, Słowik A, Szczudlik A. Predictors of poststroke dementia: results of a hospital-based study in Poland. Dementia Geriatric Cogn Dis 2006;21:328-34.

22. Pendlebury ST, Rothwell PM. Prevalence, incidence, and factors associated with pre-stroke and post-stroke dementia: a systematic review and meta-analysis. Lancet Neurol 2009;8:1006-18.

23. Tamam BT, Nebahat Tamam Y. The prevalence of demena three months after stroke and its risk factors. 2008;19:46-56.

24. Al-Qazzaz NK, Ali SH, Ahmad SA, Islam S. Cognitive assessments for the early diagnosis of dementia after stroke. Neuropsych Dis Treat 2014;10:1743.

25. Kalaria RN, Akinyemi R, Ihara $M$. Stroke injury, cognitive impairment and vascular dementia. Biochim Biophys Acta 2016; 1862:915-25.

26. Choi S-JJ, Sung-Soo Y, Young-Sun S, et al. Prevalence of Alzheimer's dementia and its risk factors in communitydwelling elderly Koreans. Psych Invest 2008;5:78-85.

27. Fagundes SDS, Tolentino Thees M, Reis Silva Pereira MF, Gomes M.
Prevalence of dementia among elderly Brazilians: a systematic review. Sao Paulo Med J 2011;129:46-50.

28. Desmond DW, Moroney JT, Sano M, Stern Y. Incidence of dementia after ischemic stroke results of a Longitudinal Study. Stroke 2002;33:2254-62.

29. Yang LJ, Xiaoqing Yan, Jing J, et al. Prevalence of dementia, cognitive status and associated risk factors among elderly of Zhejiang province, China in 2014. Age Ageing. 2016:afw088.

30. Béjot Y, Aboa-Eboulé C, Durier J, et al. Prevalence of early dementia after firstever stroke a 24-year population-based Study. Stroke 2011;42:607-12.

31. Cummings JL, Benson DF. Dementia: a clinical approach. London: Butterworth-Heinemann Medical; 1992.

32. Mackowiak-Cordoliani M-A, Bombois S, Memin A, et al. Poststroke dementia in the elderly. Drugs Aging 2005;22:483-93.

33. Mirza SS, Portegies ML, Wolters FJ, et al. Higher education is associated with a lower risk of dementia after a stroke or TIA. The Rotterdam study. Neuroepidemiology 2016;46:120-7.

34. Ott A, Breteler MM, de Bruyne MC, et al. Atrial fibrillation and dementia in a population-based study. Stroke 1997;28:316-21.

35. Knecht S, Oelschläger C, Duning $T$, et al. Atrial fibrillation in stroke-free patients is associated with memory impairment and hippocampal atrophy. Eur Heart J 2008;29:2125-32.

36. Inzitari D, Di Carlo A, Pracucci G, et al. Incidence and determinants of poststroke dementia as defined by an informant interview method in a hospital-based stroke registry. Stroke 1998;29:2087-93.

37. Ott A, Breteler MM, de Bruyne MC, et al. Atrial fibrillation and dementia in a population-based study the Rotterdam Study. Stroke 1997;28:316-21.

38. Zhang M. [Prevalence study on dementia and Alzheimer disease]. Zhonghua yi xue za zhi. 1990;70:424-8.

39. Censori B, Manara O, Agostinis C, et al.
Dementia after first stroke. Stroke 1996;27:1205-10.

40. Saczynski JS, Sigurdsson S, Jonsdottir MK, et al. Cerebral infarcts and cognitive performance. Stroke 2009;40:67782.

41. Pohjasvaara T, Erkinjuntti T, Ylikoski $\mathrm{R}$, et al. Clinical determinants of poststroke dementia. Stroke 1998;29:75-81.

42. Kokmen E, Whisnant J, O'Fallon W, et al. Dementia after ischemic stroke. A population-based study in Rochester, Minnesota (1960-1984). Neurology 1996;46:154-9.

43. Gorelick PB, Brody J, Cohen D, et al. Risk factors for dementia associated with multiple cerebral infarcts: a casecontrol analysis in predominantly African-American hospital-based patients. Arch Neurol 1993;50:714-20.

44. Ikram MA, van Oijen M, de Jong FJ, et al. Unrecognized myocardial infarction in relation to risk of dementia and cerebral small vessel disease. Stroke 2008;39:1421-6.

45. Aronson M, Ooi W, Morgenstern H, et al. Women, myocardial infarction, and dementia in the very old. Neurology 1990;40:1102-5.

46. Tatemichi T, Desmond D, Paik M, et al. Clinical determinants of dememtia related to stroke. Ann Neurol 1993;33:568-75.

47. Zhang T, Pan B-S, Zhao B, et al. Exacerbation of poststroke dementia by type 2 diabetes is associated with synergistic increases of $\beta$-secretase activation and $\beta$-amyloid generation in rat brains. Neuroscience 2009;161:1045-56.

48. Nys G, Van Zandvoort M, De Kort P, Jansen B, Van der Worp H, Kappelle L, et al. Domain-specific cognitive recovery after first-ever stroke: a follow-up study of 111 cases. J Int Neuropsychol Soc 2005; 11:795-806.

49. CROXSON SC, JAGGER C. Diabetes and cognitive impairment: a community-based study of elderly subjects. Age Ageing 1995;24:421-4.

50. Desmond DW, Moroney JT, Sano M, Stern Y. Recovery of cognitive function after stroke. Stroke 1996;27:1798-803. 